Walking on Glass

\title{
Walking On Glass
}

\section{Introduction}

Tower Bridge, spanning the Thames, is a historic site, a busy thoroughfare, a tourist attraction and an exhibition center. Visitors come to marvel over the construction of the Victorian engine rooms, or to watch the bridge slowly lift to allow ships through. Since the 1980s the public have been able to experience another spectacle: a view of London from the high walkways, 42 meters above the river, that span from one tower to the other. These walkways offer an additional thrill for visitors, as the central stretches are constructed of glass floor panels. ${ }^{1}$

\section{Fig. 1}

In November 2015 I was invited to take part in a public relations marketing exercise for Tower Bridge. The event was called The Glass Floor Challenge: Conquer Your Fear of Heights at the World's Most Famous Bridge. ${ }^{2}$ The proposal was to meet Sean Fletcher, a presenter for the TV show Good Morning Britain who experiences vertigo, and offer him somatic (mind-body) practices for crossing the glass walkways, tools that might alleviate his symptoms of dizziness and wobbliness. Our meeting was filmed and broadcast the following morning in a program about common phobias. ${ }^{3}$

This writing documents that event, from the perspective of artistic practice, drawing on my experiential knowledge as a dancer, psychotherapist and somatic movement practitioner. At the time of invitation, I was involved with a cross-disciplinary research project that focuses on acts of falling - physical, metaphorical and psychological. The Tower Bridge event tempted me with a complementary strand of enquiry, an opportunity to engage with the phenomenon of acrophobia - fear of heights and fear of 
falling. The Tower Bridge event is presented here, for the most part, as a 'what if' autoethnographic proposition. My idea behind the venture was that a somatically informed relationship between body and ground might help to alleviate sensations of falling associated with acrophobia. Reflecting on the wider processes and practices surrounding the event, this writing raises questions around sensory awareness, the body's relationship to gravity, and emotions (especially fear) of heights, contributing to broader debates on bodies, feeling and vertical space.

Before the filmed event with Sean I undertook fieldwork, to experience walking the glass floor myself and to observe others. I was curious. What if I experienced vertigo myself? Could I cross the glass walks? How might somatic body awareness support me while crossing? The following section presents reflections on the embodied experience of walking on the glass floor, before the paper moves on to consider the potential of somatic movement practice to alleviate a fear of heights. To support this 'what-if' scenario, I call on a process of potency (as used in homeopathy) and 'window of tolerance' (as used in sensorimotor psychotherapy).

\section{Fieldwork}

I feel nervous as I walk towards the edge of the glass. What if the glass shatters under my weight and I fall to my death below? Countering this egotistical fantasy is another internal voice telling me the structure is safe and I am fairly insignificant in the grand scheme of weighted things. Even so, as I walk towards the glass I am experiencing the same adrenalin rush of fear/excitement that I experience before a fairground ride, or a mountain pass. 
I step on the glass. I cross back and forth several times, familiarizing myself with adrenalin rush while I try out my somatic movement tools of support. The different speeds and directions of vertical and horizontal movement happening far below impress me. There are people walking, cyclists, cars and buses, moving at different speeds, moving up and down the two lane roadway below, activity that moves in parallel with the walkway. Then there is the river, choppy waves and fast flowing water, flowing horizontally to the walkway. As I walk the glass I can sense how any attempt to fix perception on these different active movement pathways below could disorientate a person's sense of balance. Perception is playing tricks.

Standing to one side, I watch as two teenage boys run from the far end of the walkway. As they approach the edge of the glass section they jump, landing well into the middle of the glass panels and they laugh, high on the release and relief of their experience. They do it again, running from the opposite end, jumping as before. A young woman holding a camera with protruding lens, walks nonchalantly onto the glass, seemingly disinterested, her intention is to film from one of the side windows, unconcerned and oblivious to what is below her. A baby crawls and sits, looking down, looking around, with open curiosity. An elderly couple approaches the glass holding hands. I sense they have made a pact together before coming. They seem determined to walk across. They step onto the glass in unison and cross slowly, holding hands throughout, plodding stiffly, faces serious, without turning to look at one another. They hold their bodies upright and look straight ahead. When they get to the other side they smile at each other - task accomplished! A gaggle of teenage girls tease and push each other onto the glass, daring each other to cross over. Eventually the entire group moves slowly across, clinging onto each other, bumbling into each other's bodies, shrieking with high-pitched 
laughter and excitement as they reach the center and look down, camaraderie seeming to outweigh any focus on what they might actually be seeing.

\section{Fig. 2}

Other people come to the edge, consider the task, make jokes, but cannot take that step onto the walkway. These people grip on to the bars at the sides of the walkway, a secure structure, finding support and safety from the sights below. They walk around the outside. Curious, I ask some of them what they are experiencing as they attempt to step on the glass. They tell me: the visual sights below warp and distort, their lower backs tingle as if vertebrae have clashed together, legs become fuzzy and have a life of their own. My evaluation of this information tells me that their postural balance might be affected by the loss of reliable visual cues and as a consequence their bodies are tricking their nervous systems into fearful sensations of falling associated with vertigo.

\section{Somatic Movement Practice}

Postural balance depends on how vestibular, proprioceptive and visual systems equally impact the central nervous system (Todd 1975). Balance is constructed through a multi sensorial experience where sensations of weight, contact, touch and hearing have equal sensory input to visual cues. If we rely too heavily on visual cues, which are thrown into distortion when looking down from a great height, our bodies can feel unstable. Somatic movement practices encourage multi-sensory awareness, particularly focusing on our physical relationship to the environment, thus elements of these practices might be useful to restore a bodily sense of balance.

Mind-body-sensory integration is core to somatic movement practices, encouraging awareness that our bodies are a source of knowledge about ourselves in the world. ${ }^{4}$ 
Somatic practices draw attention to our bodies as neither static nor solid, but constantly changing and adapting in relation to our environment (Hanna 1980). Fundamental to these practices is a relationship between body, breath and ground, a creative partnership that develops environmental contact and possibilities for mind/body growth and change. Indeed, somatic practices such as Body Mind Centering (Bainbridge Cohen, 2012) and Release Technique (Elsworth Todd 1975, Matt 1993, Skinner 1999, Lepkoff 1999, Agis \& Moran 2002) have impassioned the work of site-based artists because these practices offer somatic understandings of body in relation to environment. See for instance the work of Anna Halprin, Helen Poyner, Body Earth, Sandra Reeve and Body Weather. Further, for many contemporary dancers, yielding to the ground - dancing with the ground - is like breathing out, necessary. Release Technique for instance (Skinner 1999) encourages yielding to gravity to sense support from the environment. Somatically, sensing gravity in relation to the ground is a necessary pathway for changing fixed physical patterns in our bodies, encouraging kinaesthetic understanding of our skeletal frame and release of muscles and joints, to initiate physical, emotional and psychological change.

To introduce somatic engagement with falling, as a possible way of managing acrophobia might seem paradoxical, given that the symptoms for vertigo are anxiety and sensations of whirling, dizziness and lack of balance. Surely we should be looking for ways to fix the body uprightly so as not to experience the fear. Certainly one remedy for sensations of vertigo is to look straight ahead at the horizon, and not look down, therefore fixing a visual cue. However, to embark on an adventure to experience the world from a great height must be to witness the view, not to construct a method whereby that view is ignored. 
Walking on Glass

\section{Potency}

Considering this paradox, in preparation for the Tower Bridge event, I wondered if alleviating a fear of falling through somatic awareness of body, gravity and ground, might work in a similar way to homeopathic remedies - through a method of potency. The British Homeopathic Association describes homeopathy as 'a form of holistic medicine.... based on the principle of 'like cures like' - in other words, a substance taken in small amounts will cure the same symptoms it causes if it was taken in large amounts (Hahnemann 2006). The small amounts are in fact less than small. The remedies are diluted and shaken rigorously until the original substance has all but disappeared, a process called potentization - creating potency.

The effectiveness of homeopathic remedies in treating illness continues to be widely critiqued by scientific medical researchers. This writing is not aiming to participate in the argument for, or against, homeopathy. Rather, my interest has been to appropriate, or extract, the homeopathic principle of treating like with like as potency. This curiosity regarding an active sensory engagement with a potency of gravitational pull, as a remedy for vertigo, was embedded in previous experience. In 2013 I spent a week in a dance studio, three hours a day, working with gravity, falling slowly, somatically and mindfully, casually or just letting go. Field notes from that time reveal:

After three hours I stop falling. I stand still and imagined myself falling, sensing my body's contact with the ground, without falling. My body is remembering falling, in partnership with the ground and the memory of knowing I could fall without harming myself allows me to stand without holding upwards or fixing 
Walking on Glass

perception. I am in contact with the ground, and my body requires minimal tension to remain standing. I can let go of all parts of my body and trust my bones that are stacked and balanced one on top of the other, requiring minimal muscle tension to maintain that balance. My body, gravity and the ground are interconnected. I experience a state of continuously falling while standing still. I am not visibly moving and I am not afraid of falling.

Through this practice, I found that my contact with gravity and the ground becomes imprinted and distilled to a sensory and fluid memory, remembered on my body as potency. As I stand, walk and run in the world, this potency of falling remains with me, allowing a kind of readiness rather than resistance to falling.

Eager to experiment with somatically informed movements and trusting this notion of potency, I began the marketing event with Sean at Tower Bridge with some preparatory tasks. While being filmed I invited him to stand away from the glass walkways and begin making connections between his body, sensation and the ground. I asked him to:

Stand still and notice your breathing ... in and out. Notice the sensation of breathing, lifting and expanding on the breath in, letting go on the breath out. Close your eyes if you wish, so you can focus on internal sensations of breathing.

In particular, it was important to focus on breathing, since mindfulness of breathing supports work with psychosomatic fears (Ogden \& Fisher 2015). When we are anxious our breathing tends to be high, fast and shallow and we tend to disconnect from sensing our bodies in the environment. We breathe in and forget to breathe out. In contrast, 
Walking on Glass

with each out breath we connect to the gravitational pull of our environment. So each breath out evokes the potency of a small fall. Thus, regulating breathing is a somatic tool for self-support that creates emotional as well as physical safety, which I now turn to consider.

\section{Emotions, anxiety and tolerance}

Most people experience a range of different emotional states during each day with spontaneous healthy adaptive responses when engaging with others and the environment. Situations perceived as threatening, such as an acrophobic experience, can cause states of hyper arousal, 'preparing us to flee, fight, freeze' or hypo arousal states where we shut down, 'become still and immobile' (Ogden 2015 p.225). In the context of sensorimotor psychotherapy, creating a window of tolerance (Dan Siegel 1999) between these extremes is a primary concern for therapists. The window of tolerance refers to an optimal zone between extremes of arousal where emotional and physiological experience can be processed without triggering further anxiety.

\section{Fig. 3}

The core work for discovering a person's window of tolerance is somatic and sensory (Ogden 2015). Sensorimotor and somatic based psychotherapies begin with identifying triggers, mindfully noticing which actions trigger hyper arousal to increase beyond the window of tolerance and which thoughts support a return to the window of tolerance. In this way a space of experience is created that is 'safe but not too safe' (Bromberg 2006 cited in Ogden 2015 p.746). 
Walking on Glass

Maintaining an awareness of breathing, the next preparatory task I shared with Sean during the Tower Bridge filming experience was designed to test his window of tolerance. Continuing to stand aside from the walkways I directed him to:

Notice your feet on the floor. Feel your weight equally placed over both feet. Sense your feet in contact with the floor. Bend and straighten your knees gently. Begin to sway forward just slightly, and come back to center. Repeat swaying backwards and come back to center. Repeat side to side. Experiment with swaying, exploring the limits of your balance, each time coming back to center. Now pause when you sense your center. This is your safe zone. Move slightly and gently, back and forth, side-to-side, down and up - keeping in constant fluid motion always returning to your safe zone.

Extend the swaying into stepping, forward and back, side to side, bending your knees, sensing your feet on the floor, returning to center in between each move and notice your breathing. Attend to how you and the ground are equally contacting one another.

Rather than aiming to 'brace' the body against gravity, and fix visual cues, the aim of the task of swaying is to notice gravitational pull through sensing weight and touch, whereby the sensation of falling becomes an action of yielding towards and pushing away in a contact dance with the ground. Through this active pattern of yield and push (Frank 2011) we can discover an embodied center of gravity as a steady base, so that fixing a gaze is no longer the primary support. Swaying between boundaries of balance within a window of tolerance helps to evoke and develop a sensation of falling-not- 
Walking on Glass

falling as potency. Through swaying - the gentle action of yielding towards and pushing against the floor - Sean might discover a space/place where a sensation of falling becomes a potency, not physically or fearfully experienced yet not so far removed to be non-existent.

Having established self-support and a safe but not too safe awareness of body, gravity and ground, I directed Sean through a final preparatory task before walking on glass.

If you feel confident with this embodied practice, let your eyes look without focusing on a specific object. Just look. Now take your gaze down towards the ground - just looking, without fixing. Look upwards, above your horizon line. Play with looking in different directions and come back to looking ahead, but without fixing. Think of this as a physical movement for your eyes, allowing the muscles in your eyes to release into movement rather than aiming for a goal of identifying something in order to balance. Breathing, swaying, bending, walking and looking, gives attention to these embodied acts as sensations, actions in relation to the environment around you.

The emphasis in this task is to experience looking as a fluid practice and a process, not a primary sense that fixes the world visually and overpowers other sensations of contact with the environment, such as weight, touch and hearing.

\section{Walking on glass}

Following the preparatory work described above, for which we had a maximum of ten minutes, Sean and I crossed the glass walkway three times. On the first walk we focused 
on breathing and contact with the ground while looking straight ahead. On the second walk I asked Sean to look down and up now and again, just looking, not fixing, while continuing an awareness of breathing and sensing his feet on the glass floor. During the third walk we paused in the center of the glass panels, regulating breathing, gently swaying back and forth, bending and stretching our knees, sensing the structure of the glass beneath our feet while looking down, making aware contact between our bodies and the glass floor. We were being with a potency of falling within a safe level of tolerance without gripping focus and able to observe what is below.

\section{Fig. 4}

Our time together was short. Filming took approximately 15 minutes. The event was for the most part a whimsical publicity stunt initiated by Tower Bridge marketing to sell a spectacular tourist attraction. Sean, as TV presenter, was performing to camera while I was attempting to engage in a one to one dialogue with him, introducing an internally focused somatic experiment to alleviate a fear of heights while he was focusing externally towards camera. At the same time I was also performing. There was no time for reflective feedback. I approached the entire event with a curious 'what if' attitude, and given the light-hearted, experimental, non-scientific context I cannot offer results, positive or otherwise.

What did become clear to me is how I am working with paradox. At the heart of this practice-led event is a sensory engagement of contact between body and ground, yielding to the environment, with an emphasis on breathing out. This practice seems contradictory in a discussion about managing a fear of heights and will no doubt be questioned by sufferers of acrophobia. Yet in support of this paradoxical use of somatic movement practice, and as a consequence of the experiment, I am discovering two 
Walking on Glass

themes that are relevant, parallel and supportive. Firstly, the homeopathic principle of treating like-with-like through substance potency and secondly, the principle of a safebut-not-too-safe window of tolerance offered by a multi sensory relationship between body and environment.

This paradoxical sensing of body, gravity and ground as a somatic potency for each person, experienced within a window of tolerance, may be key to further exploration; not so much that anxiety is triggered, but not so little that creative change cannot be experienced. Exploring the potency of embodied gravitational pull, that will stimulate sensory change without overwhelming the body with fear of falling, suggests practiceled research to be investigated in more depth following this Tower Bridge marketing event. 
Walking on Glass

References

Agis, G. \& Moran, J. (2002), 'In Its Purest Form a rare insight into the work of Joan Skinner', in Animated, winter 2002, p. 20-22

Bainbridge Cohen B. (2012) Sensing, Feeling, Action $3^{\text {rd }}$ Edition Toronto Ontario: Contact Editions

Bromberg, P.M. (2006) Awakening the Dreamer: Clinical Journeys Mahwah, NJ: Analytic Press

Frank, R. and LeBarre, F. (2011), The First Year and the Rest of Your Life, New York: Routledge.

Hanna, T (1980) The Body of Life: Creating New pathways for Sensory Awareness Rochester Vermont: Healing Arts Press

Hahnemann, S. (2006) The Organon of Medicine $6^{\text {th }}$ edition UK: Gazelle distribution Trade

Johnson, D.H. (1986) (eds.), Bone, Breath and Gesture; practices of embodiment Volume 1 North Berkeley C.A. Atlantic Books

Lepkoff, D. (1999) 'What is Release Technique?' in Movement Research Performance Journal Fall/Winter 1999 \#19 
Walking on Glass

Matt, P. (1993) A Kinesthetic Legacy: The Life and Works of Barbara Clark USA: CMT Press

Ogden, P. \& Fisher, J. (2015) Sensorimotor Psychotherapy New York NY: W.W.Norton \& Company

Siegel, D. (1999) The Developing Mind New York NY: Guilford Press

Skinner, J. (1999), 'Skinner Releasing Technique' in Allinson (ed.), The Illustrated Encyclopedia of body-mind disciplines, New York, NY: Rosen Publishing Group, p. 265267

Sweigard, L. (1974) Human Movement Potential: Its Ideokinetic Facilitation U.S.A.: Allegro Editions

Todd, M.E. (1975) The Thinking Body: Study of the Balancing Forces of Dynamic Man Hightstown NJ: Princeton Book Company

\footnotetext{
${ }^{1}$ The glass floor across each Walkway comprises of six panels, each weighing 530 kilograms, supported by a carbon steel framework weighing approximately 1,000 kilograms. The Walkways original steel lattice structure has been preserved under the glass.

2 http://www.towerbridge.org.uk/Glass-Floor-Challenge/

3 http://www.itv.com/goodmorningbritain December 4th 2015.

4 The most familiar somatic movement forms to influence Western dance since the 1970s are Release Technique, Alexander Technique, Body Mind Centering, Authentic Movement and Feldenkrais. Earlier somatic influences can be explored in the work of Laban Movement Analysis and Bartenieff Fundamentals. Somatic pioneers include Mabel Ellsworth Todd (1975), Barbara Clarke, Eugene Gindler, Alexander, Reich, Feldenkrais, Klein, Schultz and Jacobson (Johnson 1986).
} 